\title{
Essential Basic Bacteriology in Managing Musculoarticuloskeletal Infection: Bacterial Anatomy, Their Behavior, Host Phagocytic Activity, Immune System, Nutrition, And Antibiotics
}

\author{
Myung-Sang Moon ${ }^{1,2}$ \\ ${ }^{1}$ Moon-Kim's Institute of Orthopedic Research, Seoul, Korea \\ ${ }^{2}$ Cheju Halla General Hospital, Jeju, Korea
}

Surgery-related infections have not been irradicated until now. To solve this problem, it is important to know the relationship between bacterial anatomy and bacterial behavior in the tug-of-war between host and pathogen. In this article, bacterial anatomy and functional behavior, host phagocytic activity, immune system, nutrition and antibiotics are reviewed to win the war against the tiny invaders and leave the host unharmed. My suggestion is that scientists should direct their studies not only to developing potent new antibiotics that will never give rise to drug-resistant mutants, but also to developing a very competitive immune system that can suppress or control infection without the aid of antibiotics.

Keywords: Infection; Bacteria; Immune; Antibiotics

\section{Introduction}

I am pleased to write this article for young orthopedic and trauma surgeons, including spine surgeons and clinical scientists, to stimulate them to pay attention to musculoarticuloskeletal infection, because we clinicians have failed to eradicate surgery-related infections. I confess that have been ignorant of the relations between bacterial anatomy and bacterial behavior in the tug-of-war between host and pathogen.

In this article [1-8], I first review bacterial anatomy and functional behavior, because it is essential to know why short-course antibiotic therapy is effective for most pyogenic infections, whereas long-term combined che- motherapy is necessary for tuberculosis and leprosy. Most clinicians, including me, have blindly used the drug formulas recommended by their seniors. It is time for us clinicians to be more wise and knowledgeable in managing infection by having more knowledge about causative organisms and host defense mechanisms. It is important for us to understand bacterial behavior associated with their anatomy, their generation time (division time), drug targets, drug responses, the efficacy of combined drugs and of monotherapy, and acquisition of resistance against antibiotics. In the second part of the article, I review host defense mechanisms, including phagocytosis [9-11].

Microbial cells face environmental stress, enduring extreme changes in temperature and salinity. They may live

Received Sep 25, 2018; Accepted Oct 1, 2018

Corresponding author: Myung-Sang Moon

Moon-Kim's Institute of Orthopedic Research, Shibum APT 14-105, 45 63-ro, Yeoungdeungpo-gu, Seoul 07344, Korea

Tel: +82-2-780-5387, Fax: +82-2-785-6065, Email: msmoonos@hotmail.com 
independently in the outside world. Consequently, they must develop mechanisms to handle osmotic pressure, which can be looked at as the mechanisms that keep the outside of the bacterial cell out and the inside in. Failure to do so is lethal for the organism. To accomplish this, bacteria construct complex cell walls. Again, pathogens face the chemical defenses of their hosts. To meet these threats, microbes build complex structures, such as the cell envelope with tensile stress. Within the cytoplasm, molecular devices such as the ribosomes, the nucleoid, and other organelles are constructed and expanded. Clinically, the structures of the ribosomes and the cell envelope material of bacteria are the targets for new antibiotics.

Pathogenic bacteria use a variety of structures and substances to overwhelm host defenses, while the host with the aid of antibacterial drugs uses nonspecific and specific defense mechanisms to stop the infection. The structurefunction relationships of the bacterial cell show how bacterial structure influences the development of disease. Bacterial structure has evolved over time. The evolution continues through genetic mutation so that the struggle of the host against the pathogen is continuously unfolding.

Bacteria can be divided into two major groups based on the differential Gram stain. The staining effect depends on the components of the cell walls (Table 1). The Grampositive cell wall is rich in peptidoglycan with multiple layers of meshwork, whereas Gram-negative cells contain very little peptidoglycan and are normally less sensitive to penicillin than are Gram-positive organisms. Thus, Gram-negative bacteria lack the environmental protection seen with Gram-positive bacteria. However, Gramnegative bacteria acquire additional protection through the presence of an outer membrane known as the lipopolysaccharide layer that is composed of lipids, proteins, and polysaccharides instead of the standard phospholipid

Table 1. Cell membrane characteristics of Gram-positive and -negative bacteria

\begin{tabular}{lll}
\multirow{2}{*}{ Compositions } & \multicolumn{2}{c}{ Gram stain for bacteria } \\
\cline { 2 - 3 } Peptidoglycan & -Positive & \multicolumn{1}{c}{-Negative } \\
\hline Teichoic acid & Present & Absent \\
\hline Lipids & Very little & Lipopolysaccharide layer \\
Outer membrane & No & Yes layer \\
\hline Toxins & Exotoxins & Endotoxins \\
Sensitivity to antibiotics & - & \\
\hline
\end{tabular}

molecules. Lipoprotein molecules fasten the outer membrane of the cell to the peptidoglycan layer of the cell wall. The outer membrane serves as a major barrier to the outside world and contains specialized proteins called porins. These proteins contain channels that vary in size and specificity, which are responsible for the passage of molecules and ions into and out of the Gram-negative cell. The size of the channel in the porin has a role in determining which substances can be moved into or out of the cell. Some bacteria reduce the permeability of their membranes as a way of keeping antibiotics out. This is accomplished by turning off the production of porin and other membrane channel proteins.

The outer membrane of Gram-negative bacteria hinders the passage of hydrophilic substances. However, there is another transporting system in the membrane, known as the porin protein channel, through which substances can pass passively. For example, in Escherichia coli, the size of the porin hole allows the passage of disaccharides, whereas in Pseudomonas aeruginosa, the hole is rather smaller. Thus, Pseudomonas is more drug-resistant. The lack of efficacy of macrolides against Gram-negative bacteria is due to failure of the drug to pass through the porins. Porin $\mathrm{D}_{2}$ allows the passage of eosinophilic amino acids, and carbapenems can also pass partially through the porin holes. Accordingly, porin $\mathrm{D}_{2}$-deficient strains become resistant to imipenem. The superior antimicrobial effect of imipenem is due to its superior permeability in comparison with other $\beta$-lactams.

Most pyogenic bacteria, regardless of their stainability, have redundant nutrient channels, although some differences may be present. Their division rates are similar and are less than 30 minutes. Based on their anatomy and function, these bacteria can respond immediately to an administered antibiotic, and thus infection can be controlled in a short period of time, within 3-6 weeks, until normalization of the erythrocyte sedimentation rate. Antibiotics work more effectively against rapidly replicating new daughter bacteria, which must build up their own structure, including the cell wall and cytoplasm.

Readers are frequently confused by the terms used to describe the so-called cell sack (bag), such as envelope, cell wall, outer membrane, inner membrane (cell membrane), and capsule. Fig. 1 is provided to help the reader understand these anatomical terms. The bacterial cell consists of the cell sack (envelope) and its contents (cytoplasm). The envelope consists of four layers, starting 
Table 2. Subcellular location of proteins in Gram-negative bacteria

\begin{tabular}{|c|c|}
\hline Cell fraction & Proteins (examples) \\
\hline Cytoplasm & $\begin{array}{l}\text { Glycolytic enzymes } \\
\text { Biosynthesis of amino acids } \\
\text { Cytoplasmic chaperones }\end{array}$ \\
\hline $\begin{array}{l}\text { Inner membrane } \\
\text { (cell membrane) }\end{array}$ & $\begin{array}{l}\text { Proton-translocating ATP synthase } \\
\text { Electron transport chain } \\
\text { Transporters for ions, sugars and amino acids }\end{array}$ \\
\hline $\begin{array}{l}\text { Periplasm (peri- } \\
\text { plasmic space) }\end{array}$ & $\begin{array}{l}\text { Sugar taxis receptors } \\
\text { Periplasmic chaperones }\end{array}$ \\
\hline Outer membrane & $\begin{array}{l}\text { Porins for sugars and petides } \\
\text { Sugar-binding proteins }\end{array}$ \\
\hline
\end{tabular}

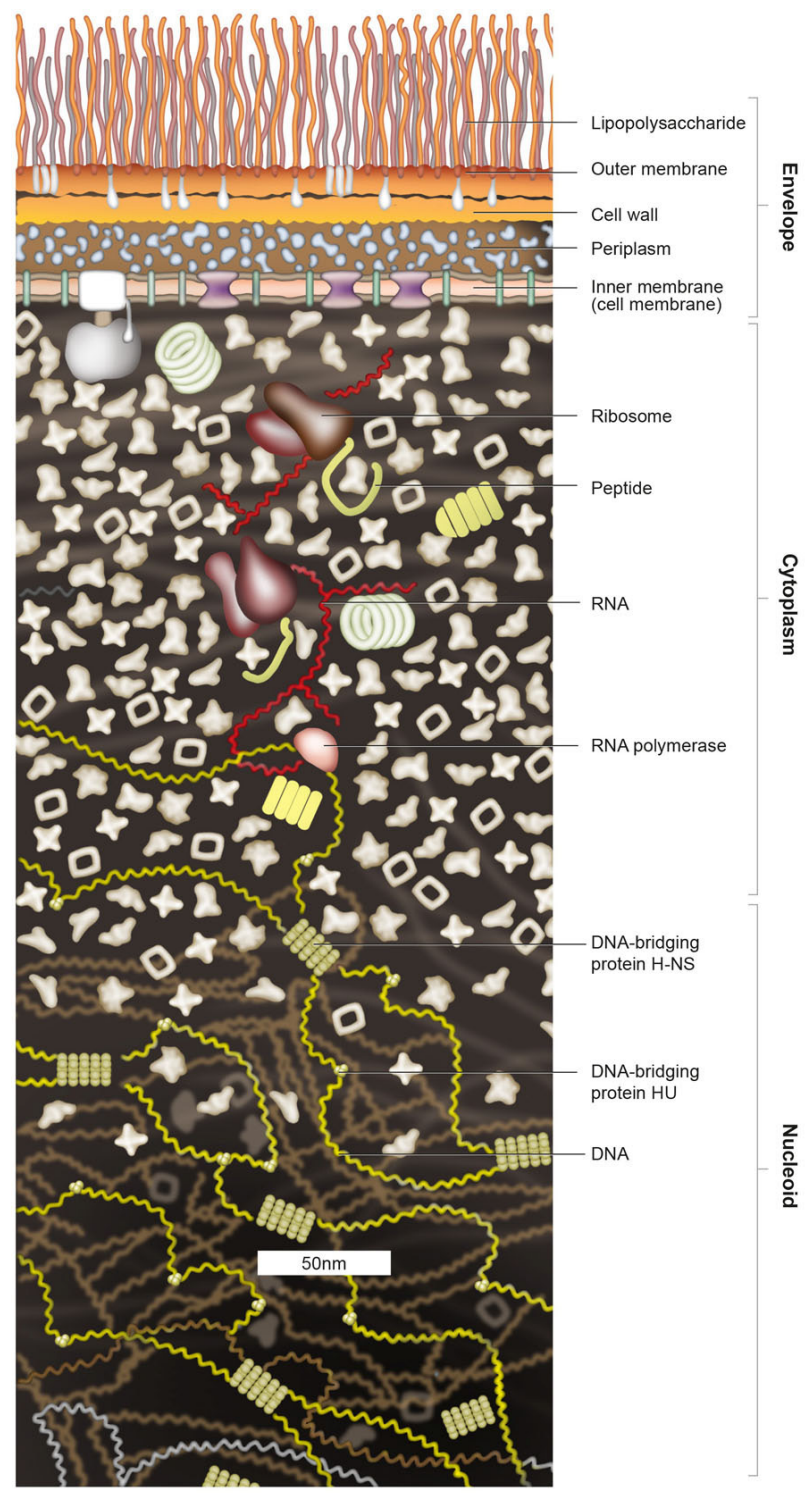

Fig. 1. Model of the bacterial cell.
Table 3. Bacterial cell components (examples)

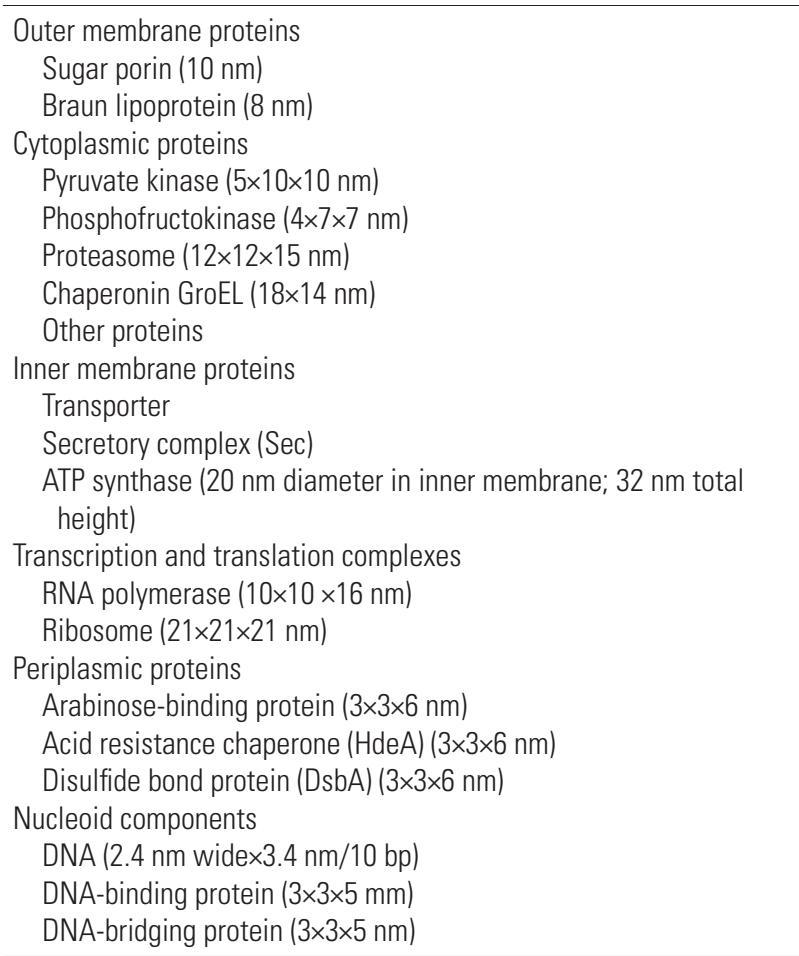

from the surface: lipopolysaccharide, outer membrane, cell wall, and periplasm. The inner membrane (cell membrane), which is located just below the periplasm, is not included in the envelope. The cytoplasm consists of a gellike network composed of proteins and other macromolecules. Ribosomes and other organelles are also found in the cytoplasm (Tables 2, 3, Fig. 1) [4].

The glycocalyx is a sticky substance composed of polysaccharides and lipopolypeptides that are produced in the cytoplasm and secreted to the outside of the cell, where they become fastened to the cell wall in two distinct ways. If the molecules are loosely attached to the cell wall, the glycocalyx is referred to as a slime layer. If the molecules form a highly organized structure that adheres tightly to the cell wall, the glycocalyx is referred to as a capsule. Both the capsule and the slime layer give the bacterial cell the ability to adhere to surfaces.

Gram-negative bacilli have two layers of membrane, the inner and outer membranes. The outer membrane does not allow easy passage of hydrophilic substances. Instead, there are passive permeating channels, the so-called porin protein channels (holes), through which substances can pass. In E. coli, the porin channel is rather small, which scarcely allows passage of macrolides in Gram-negative bacilli. The lack of efficacy of macrolides against Gram- 
negative bacteria is due to failure of the drug to pass through the porins.

\section{Bacterial Cell Wall}

Gram-positive cell walls are easy to identify because of the numerous layers of peptidoglycan. In addition to wallassociated proteins, the Gram-positive wall contains teichoic acid and lipoteichoic acid. The latter type spans the entire peptidoglycan layer and fastens the cell wall to the underlying plasma membrane. The structure of this wall has a direct bearing on how certain antibiotics function and on how the Gram stain is performed.

The Gram-negative cell wall contains very little peptidoglycan and no teichoic acid. One of the most prominent features of the Gram-negative wall is the outer membrane, which is composed of lipopolysaccharides, lipoproteins, and phospholipids. The Gram-negative cell wall contains endotoxins that can cause toxic shock, and the O polysaccharides in the wall can be used diagnostically.

\section{Pyogenic Bacterial Structures Outside the Bacterial Cell Wall}

There are five structures that can be found outside the cell wall of a bacterium. Not all bacteria have all of those structures. Three of them, the glycocalyx, fimbriae, and pili, are primarily involved with adherence (the requirement of staying inside the host), and the flagella, axial filament, and also the pili are involved with motility (which can be used to defeat host defenses and damage the host). Most pyogenic bacteria have one of these five structures outside the cell wall for their survival and activity. The glycocalyx protects the organism from desiccation and in desperate conditions can be used as a source of nutrition. This structure also has an important role in pathogenesis. Both Gram-positive and Gram-negative cells may possess a capsule. Some bacteria, such as Streptococcus pneumoniae, Bacillus anthracis, and Klebsiella pneumoniae, are not infectious unless they are encapsulated [5].

Even after repeated replication, some bacteria keep their planktonic form, whereas most pyogenic bacteria, particularly biofilm-producing organisms, convert from the planktonic to the sessile form in which they are confined to the biofilm community. These sessile forms of bacteria in the biofilm are clinically problematic, because antibiotics cannot reach them. Biofilms are complex, multicellu- lar, surface-attached microbial communities. Penetration of drugs into the biofilm is reduced, and stress-resistant physiology is also altered by the cells.

\section{Phagocytosis}

Phagocytosis is reviewed here to re-educate the readers to be knowledgeable clinicians in controlling infection. Infection is one of the most common ailments we humans suffer in our daily lives. To protect the host's body from infection, the host's immune and nutritional status should be enhanced to promote active phagocytosis. However, this takes time. Immediate antibiotic therapy should be started as a first step. Nutritional and immune suppression (T lymphocytes $<1,500$ ) is frequently found together with hypoalbuminemia (albumin $<3.5 \mathrm{mg} \%$ ). Based on these data, appropriate measures to improve and enhance the patient's nutritional and immune condition can be taken. Opsonization facilitates phagocytosis; antibiotics link the ingested bacteria in macrophages.

\section{Origins and Function of Blood Cells}

The following cells participate in defense against infection: basophils for inflammation; neutrophils, eosinophils,

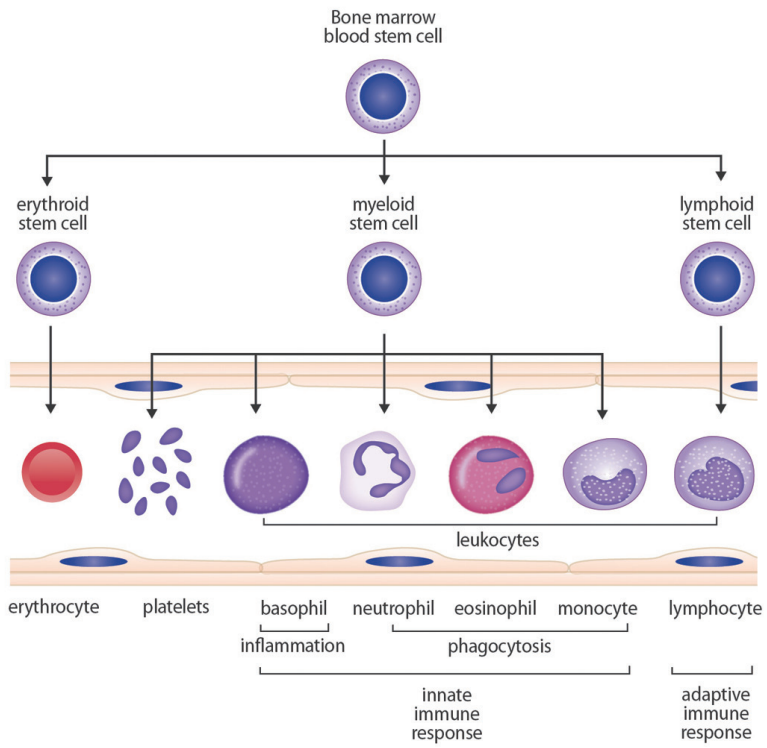

Fig. 2. Differentiation of cell types in the blood.

Stem cells in the bone marrow give rise to a variety of cell types known collectively as the blood's formed elements. Erythrocytes are red blood cells. Red blood cells and platelets are shown on the left. The remaining cells are the five types of white blood cell. Basophils, neutrophils, eosinophils, and monocytes are involved in the innate immune response. Lymphocytes function in the adaptive immune response. 


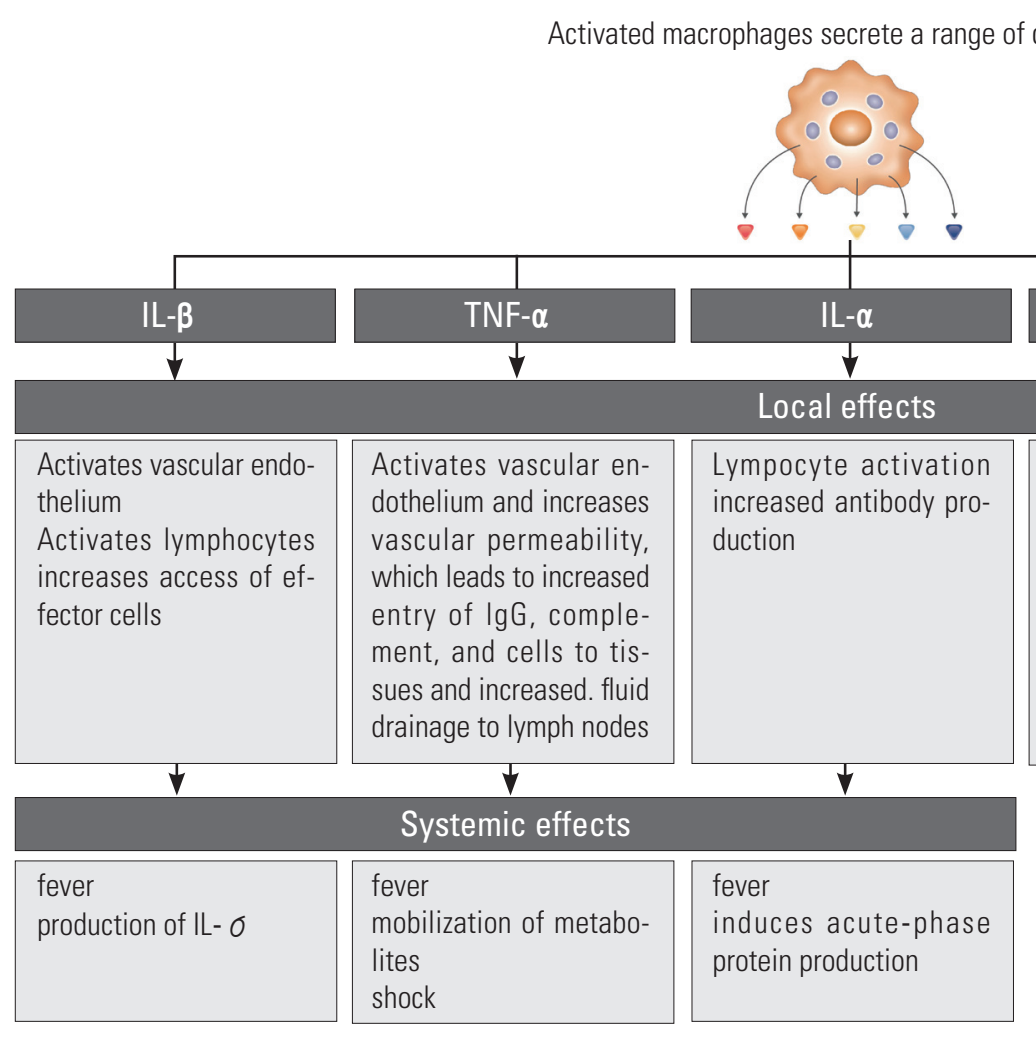

and monocytes for phagocytosis; all white blood cells except lymphocytes for the innate immune (nonadaptive) response; and lymphocytes for the adaptive immune response (Fig. 2).

Phagocytosis, the cellular mechanism in the second line of defense, is carried out primarily by neutrophils and macrophages. These two types of white blood cell are collectively called phagocytes, which means any immune system cell that performs phagocytosis (Figs. 3-4). When an infection begins, the traumatized tissue produces chemokines, and the presence of chemokines in the body signals neutrophils to move immediately to the damaged site, as noted earlier. Monocytes are the second cells to arrive at the scene; as they arrive, they differentiate into macrophages, which are more phagocytic than neutrophils.

Phagocytosis consists of five phases: chemotaxis, adherence, ingestion, digestion, and excretion.

Chemotaxis is the release of chemokines to attract phagocytes to the infected area or damaged tissue.

Adherence occurs as the plasma membrane of the phagocytic cell comes into contact with a pathogen cell. This involves binding of structures such as glycoproteins on the pathogen to surface receptors on the phagocyte. After adherence of the phagocyte's pseudopod to the pathogen, the pathogen is wrapped entirely and is in-
Fig. 3. Various cytokines secreted by activated macrophages.

\begin{tabular}{|l|l|}
\hline $\begin{array}{l}\text { Chmotactic factor recruits } \\
\text { neutrophils, basophils, } \\
\text { and T cells to sites of } \\
\text { infection }\end{array}$ \\
of CD4 T cells into Th1 \\
duces the differentiation \\
cells
\end{tabular}

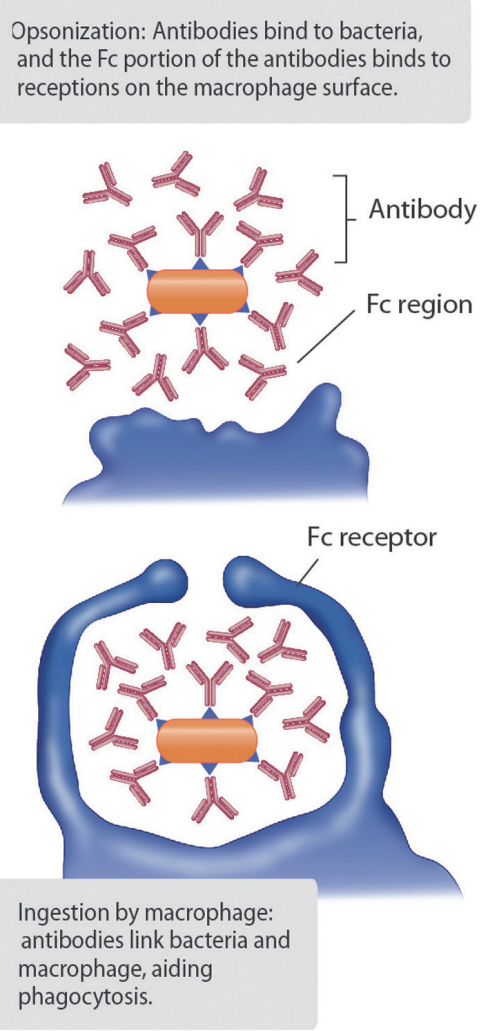

Fig. 4. Opsonization.

Opsonization is a process that facilities phagocytosis. Here macrophage Fc receptors bind to the Fc region of antibodies binding to bacteria 
gested into the phagocyte's cytoplasm. The bacterial capsule (glycocalyx) can inhibit this attachment, making the pathogen cell resistant to phagocytosis.

Ingestion: The ingested pathogen is called the phagosome, which fuses with the lysosome. In this phase, the pathogen tries to escape from phagolysosomal fusion to survive and replicate with the use of certain chemical tools. In the case of Mycobacterium tuberculosis, sulfatide inhibits this fusion to prevent the pathogen from being digested.

Digestion: After fusion of the phagocyte with the lysosome, digestion of the engulfed pathogen starts. The lysosome vesicle is filled with enzymes such as lysozyme, lipase, protease, and ribonuclease in a low $\mathrm{pH}$ (4.0) environment. Phagolysosomal fusion process can occur in as little as 30 minutes. Macrophages use oxygen derivatives such as hydrogen peroxide and hypochlorite ions for the digestion phase. All oxygen derivatives work by destroying the pathogen's plasma membrane.

Excretion (final phase) takes place after digestion of the pathogen. The phagolysosome, now filled with pathogen fragments, referred as a residual body, moves to the surface of the phagocyte and expels the debris.

Phagocytosis can be compromised in several ways:

Chemotherapy and/or radiation induce a deficient phagocytic response.

Acquired immunodeficiency syndrome causes loss of the phagocytic response.

Drug treatment for $R$. A. and organ transplantation decreases the ability of the innate immune system to respond.

In summary, phagocytosis is a powerful tool in the host defense response. However, in this tug-of-war between phagocytes and bacteria, bacteria have evolved ways to defeat this host defense. Some bacteria produce enzymes called leukocidins that destroy white blood cells, thereby removing the phagocytic threat. Other bacteria have capsules that interfere with the adherence phase of phagocytosis and also resist digestion. A bacterium that can resist destruction while inside a phagocyte can remain hidden from the powerful and specific adaptive immune response.

\section{Role of Chemical Signals in Phagocytosis}

Among the four chemical signals participating in the inflammatory processes, three (kinins, prostaglandins, and leukotrienes) are effective against infectious processes:

Kinins are released from the damaged tissue and draw phagocytes to the site of injury.

Prostaglandins intensify the effect of kinins and also help in the migration of phagocytes through the blood vessel wall.

Leukotrienes, produced by mast cells, increase vascular permeability and promote the adherence phase of phagocytosis.

Chemokines are released by mast cells around the infection in response to the presence of the bacterial invader. They also have a role in the destruction of pathogens. Neutrophils exposed to CXC-L8 and the cytokine TNF release oxygen atoms in free radical form and nitric oxide, two powerful antimicrobial toxins that cause cellular lysosomes to release their contents (Fig. 3).

Lysosomes are the organelles responsible for destroying invading microorganisms and any other foreign materials that get inside the cell. They are produced by the Golgi apparatus and bud off as vesicles containing powerful enzymes that destroy the invaders. Lysosomes are also responsible for recycling any host cell components that are no longer needed or are no longer functioning properly. The enzymes in lysosomes break down these components and get rid of anything that is not recycled. Any inhibition of lysosomal function can be a lethal event for the eukaryotic (host) cell.

\section{Enhancement of Activity of the Immune System}

One of the two immune systems is innate (nonacquired) immunity. A component of the innate immune response is complement (consisting of several soluble protein factors), which is constantly present in the blood and forms holes in the bacterial membrane, thereby killing the microbe. On the other hand, the adaptive immune response generates specific antibodies to bacterial cells that have escaped the innate mechanism. These antibodies are not made until well after the organism has infected a person. Together, innate and adaptive immunity can help ward off disease caused by pathogenic organisms.

\section{Duration of Antibiotic Therapy}

What is a plausible explanation for the fact that 3 to 6 weeks of administration of a single antibiotic is sufficient 
Table 4. Comparison of optimal growth temperatures and generation times for several pathogenic bacteria

\begin{tabular}{|c|c|c|c|}
\hline Microorganism & Disease & $\begin{array}{l}\text { Optimal growth } \\
\text { temperature }\left({ }^{\circ} \mathrm{C}\right)\end{array}$ & $\begin{array}{c}\text { Generation } \\
\text { time (hr) }\end{array}$ \\
\hline Escherichia coli & Diarrheal diseases, opportunistic infections, and urinary tract infections & 40 & 0.35 \\
\hline Staphylococcus aureus & Skin, respiratory, and other infections & 37 & 0.47 \\
\hline Pseudomonas aeruginosa & Nosocomial infections & 37 & 0.58 \\
\hline Clostridium botulinum & Botulism & 37 & 0.58 \\
\hline Mycobacterium tuberculosis & Tuberculosis & 37 & 12.0 \\
\hline
\end{tabular}

to control pyogenic infection in most cases, whereas in the case of tuberculosis, 9 to 12 months of tedious administration of combined chemotherapy with three or four drugs is needed? Two reasons have been suggested: differences in nutrient and drug delivery patterns due to different membrane transport mechanisms, speed, and dose; and differences in bacterial replication (division, generation) time.

Most pyogenic bacteria have good membrane transport mechanism, whereas $M$. tuberculosis depends for its nutrition solely on a few poorly developed small channels and has no carrier and nutrient-binding proteins for nutrient transport. There are also great differences in generation (doubling) time: the generation time of most pyogenic bacteria is less than 35 minutes ( 0.58 hours), whereas that of tubercle bacilli is 12 hours.

Even after antibiotic administration, all the drugexposed bacteria can repeat replication for an uncertain generation for a while. All the newborn daughter cells are assumed to be functionally debilitated and deformed due to damage by the antibiotic, and the division rate also may slow down. Finally, the causative microbes will face the death phase, which is the final goal of the maximum 6 weeks of antibiotic therapy for pyogenic infection and the minimum of 9 to 12 months of combined chemotherapy for tuberculosis.

In the case of $M$. tuberculosis, due to its cell wall structure and very slow generation time (12 hours), early efficacy is not expected because the amount of drug transported into the bacilli after drug administration is insufficient to be effective. Tubercle bacilli can divide 540 times in 9 months and 720 times if they replicate at the same speed until death at 12 months. Thus, the newly divided daughter tubercle bacilli are exposed to three or four drugs from 540 to 720 times, whereas pyogenic bacteria are exposed to antibiotics 144 times in 3 weeks and 288 times in 6 weeks of therapy. Therefore, the tubercle bacilli are exposed to antibiotics about 2.5 to 3.8 more times than are the pyogenic bacteria before reaching the cell death phase. Tubercle bacilli can only be eradicated by combining several antibiotics with different targets: isoniazid and ethambutol for the cell wall, pyrazinamide for metabolism, rifampin for RNA polymerase, and streptomycin for translocation. Multidrug (three or four drugs) shotgun therapy for at least 9 to 12 months is the only treatment to cure tuberculosis. Single drug administration, which leads to the development of resistant strains, should never be prescribed for tuberculosis.

Tubercle bacilli persist in planktonic form even after repeated replication and do not produce adhesion molecules (glycocalyx), and the thick waxy envelope of $M$. tuberculosis excludes many antibiotics and offers exceptional protection from host defenses, enabling the pathogens of tuberculosis and leprosy to colonize their hosts over long periods. However, the mycobacterial envelope also retards uptake of nutrients. As a result, $M$. tuberculosis and $M y$ cobacterium leprae grow extremely slowly and are a challenge to culture in the laboratory. For this reason, the cure of tuberculosis requires an exceptionally long course of antibiotic therapy.

\section{Bacterial Generation Time}

The bacterial generation time (Table 4 ) is the period from one generation to the next. In an environment with unlimited resources, bacteria divide at a constant interval called the generation time (Fig. 5). It is influenced by several parameters, including bacterial species, type of medium, temperature, and $\mathrm{pH}$.

The generation time for cells in culture is also known as the doubling time. Starting with any number of organisms (No.), the number of organisms after $n$ generations will be No. $\times 2^{n}$. For example, a single cell after three generations $(n=3)$ will produce: 1 cell $\times 2^{3}=8$ cells.

It is important to know the death phase of bacteria. Like 
the growth rate, the death rate, i.e., the rate at which cells die, is logarithmic. However, the death rate is a negative exponential function. When determining the development of microbial death, exact death rates are difficult to define, because mutations arise that promote survival, and some bacterial cells grow by cannibalizing others. Consequently, the cell death phase is extremely prolonged. This phenomenon is reflected clinically by drug response assessment after antibiotic therapy.

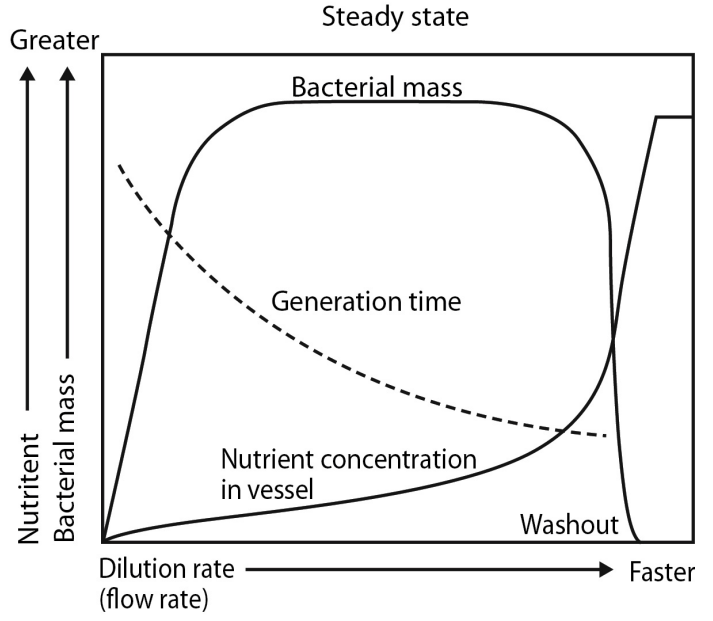

Long

Fig. 5. Relationships between dilution rate, cell mass, and generation time.

As the dilution rate increases in a chemostat (meaning more nutrient is fed to the culture), the generation time decreases (the cells divide more quickly) and the cell mass of the culture increases. This pattern continues until the rate of dilution exceeds the division rate, at which point cells are washed from the vessel faster than they can be replaced by division and the cell mass decreases. The $y$-axis varies depending on the curve, as labeled in the figure.
A fast-growing species will cause disease rapidly within days, whereas a slow-growing organism may take weeks or months. Clinically we see this phenomenon in cases of acute pyogenic infection and tuberculosis.

\section{Cell Membranes and Transport for Nutrient Uptake}

Membranes are designed to separate what is outside the cell from what is inside. For a cell to gain a substance from the environment, the membrane must be selectively permeable to nutrients the cell can use. Selective permeability of the envelope regardless of Gram stainability is achieved in three ways: by the use of substrate-specific carrier proteins in the membrane (permeases), with the aid of dedicated nutrient-binding proteins that patrol the periplasmic space, and through the action of membranespanning protein channels or pores that discriminate between substrates. Making use of these three mechanisms, most pyogenic organisms have evolved efficient transport systems that concentrate nutrients inside the cell relative to the outside. Based on these transport mechanisms, sufficient nutrients and effective drug doses can be brought into pyogenic bacterial cells. Among these three mechanisms, tubercle bacilli depend solely for their nutrition on a few very poorly developed nutrient channels (porin channels). Based on their wall structure, tubercle bacilli take in a small amount of nutrients slowly, together with drugs, and newly divided daughter tubercle bacilli are

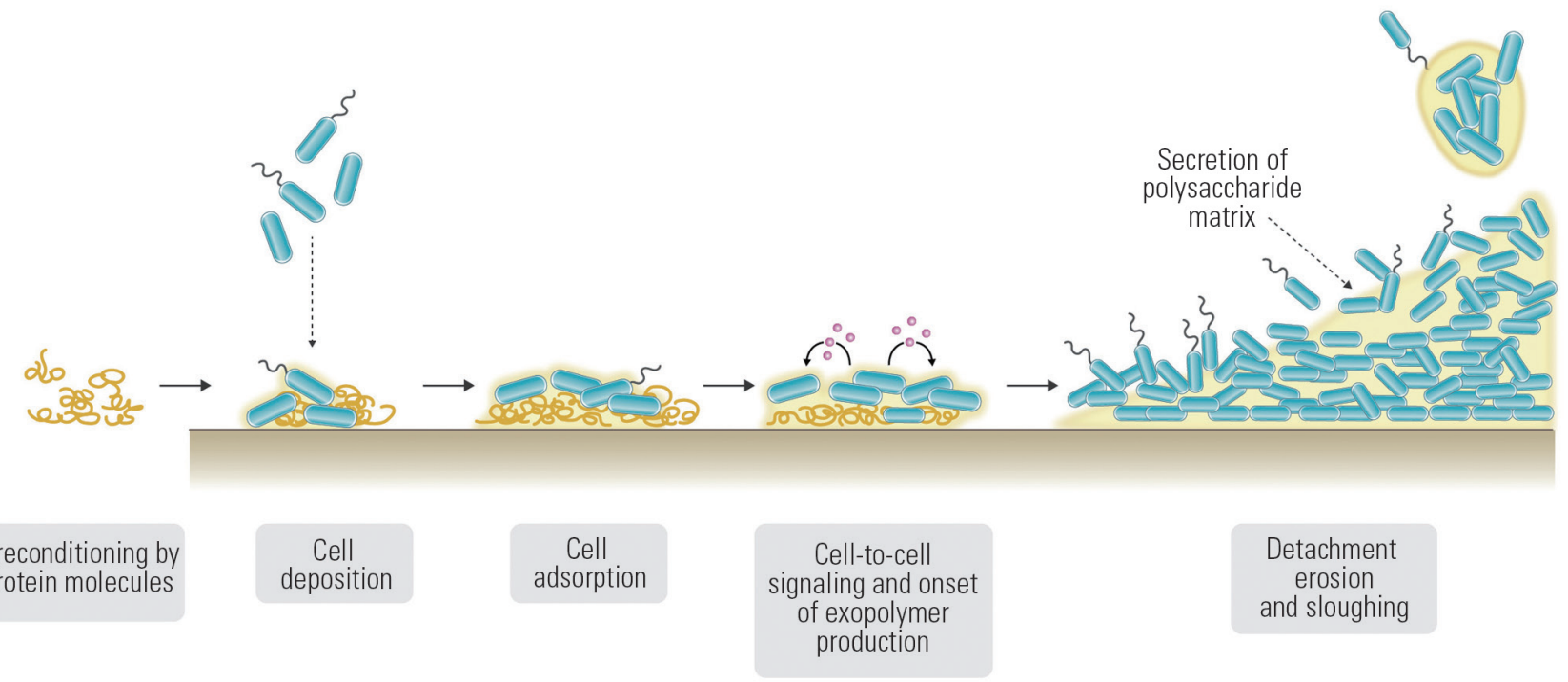

Fig. 6. Development of a biofilm.

The process starts when a film of proteins forms. Organisms adhere to these proteins and then aggregate with other organisms to produce the biofilm. 
exposed to drugs only once every 12 hours. On the other hand, bacteria that have good channels for nutrition are good drug responders, because effective drug doses can be delivered to the targeted site.

\section{Biomaterial-Centered Infection and Biofilm}

Bacteria are typically thought of as unicellular, but in nature, many, if not most, bacteria form specialized, surfaceattached communities called biofilms. Biofilms play critical roles in microbial pathogenesis and environmental quality. Distinct stages of biofilm development include initiation, maturation, maintenance, and dissolution. Bacterial biofilms form when nutrients are plentiful (Fig. 6).

A biofilm is an extracellular polysaccharide network, similar to the capsule polysaccharide that forms a mechanical scaffold around bacteria. The biofilm allows bacteria to bind to prosthetic devices like intravenous catheters and protects them from attack by antibiotics and the immune system. Imagine bacteria secreting their polysaccharide concrete around themselves to form a biological bunker. These biofilms are very difficult for antibiotics to penetrate. Biofilm development involves adherence of bacterial cells to a substrate, the formation of microcolonies, and ultimately the formation of complex channeled communities that generate new planktonic cells. Once a microcolony has been established, the cells form a thick extracellular matrix of polysaccharide polymers and entrapped organic and inorganic materials. These exopolysaccharides increase the antibiotic resistance of the residents within the biofilm. Little is known about how a biofilm dissolves, although the process is thought to be triggered by starvation.

\section{M. tuberculosis and Its Behavior}

Primary tuberculosis occurs when the host encounters tubercle bacilli for the first time. At this time, organisms will find their way to the alveoli, and a localized inflammatory response will develop. This will involve phagocytosis of the bacilli by macrophages and neutrophils. The bacilli are taken into phagosomes in the normal fashion, but then

Table 5. Bacterial anatomy \& bacterial cell targets in antibiotic therapy: pyogenic bacteria and tubercle bacilli

\begin{tabular}{|c|c|c|c|c|c|}
\hline & $\begin{array}{c}\text { Pyogenic bacteria } \\
\text { Short-term therapy (3-6 wk) }\end{array}$ & \multicolumn{4}{|c|}{$\begin{array}{l}\text { Tubercle bacilli (mycobacterium tuberculosis) } \\
\qquad \text { (9-12 mo therapy) }\end{array}$} \\
\hline $\begin{array}{l}\text { Bacterial cell wall } \\
\text { (cell membrane constituents) }\end{array}$ & $\begin{array}{l}\text { Gram+bacteria (thick layer): peptidoglycan } \\
\text { Gram-bacteria (thin layer): } \\
\text { phospholipid+lipopolysaccharide }\end{array}$ & \multicolumn{4}{|c|}{$\begin{array}{l}\text { Waxy lipid coat: } \\
\text { Mycolyl-arabinogalactan-peptidoglycan complex } \\
\text { (60\% mycolic acid) }\end{array}$} \\
\hline Nutrient channel development & $\begin{array}{l}\text { - Abundant (well developed): } \\
\text { - Good absorption of nutrients and antibiotics }\end{array}$ & \multicolumn{4}{|c|}{$\begin{array}{l}\text { - Very poorly developed channeds: } \\
\qquad \text { Limit absorption of nutrient } \\
\longrightarrow \text { and antibiotics. } \\
\text { bacillary growth. }\end{array}$} \\
\hline $\begin{array}{l}\text { - Replication (generation) time: } \\
\text { - Frequency to death phase }\end{array}$ & $\begin{array}{l}\cdot 20-30 \text { min: } \\
\cdot-48-72 \text { time/day } \\
\text { 144-288 time/3-6 wk }\end{array}$ & \multicolumn{4}{|c|}{$\begin{array}{l}12 \text { hours } \\
\qquad \text { Twice/day } \\
540-720 \text { time/9-12 mo }\end{array}$} \\
\hline Targets of antibiotics in bacteria & & INH (isoniazid) & Rifampin & Etham-butol & Pyrazina-mide \\
\hline \multicolumn{6}{|l|}{ Six targets } \\
\hline Replication & Ciprofloxacin, Novobiocin & - & - & - & - \\
\hline Wall (membrane) & $\begin{array}{l}\text { Penicillin, Cefriaxone, Imipenem, Fosfomycin, } \\
\text { Vancomycin, Polymyxin, Niazid, Ethambutol }\end{array}$ & + & - & + & - \\
\hline Ribosome (R) & $\begin{array}{l}\text { Gentamicin, Chloramphenicol, Tetracycline, } \\
\text { Srythromycin, Clindamycin, Lineziolid }\end{array}$ & & & & \\
\hline Metabolism (M) & $\begin{array}{l}\text { Sulfisoxazole, Trimethoprim, Isoniazid, } \\
\text { Pyrazinamide, Nitrofuranton }\end{array}$ & + & & & + \\
\hline RNA polymerase (P) & Rifampin & & + & & \\
\hline Translation (T) & Focidic acid, streptomycin, Mypirocin & & & & \\
\hline
\end{tabular}

PS, multitarget therapy is essential for tubercle bacilli which target single site each and must be bactericidal. 
"remodel" this structure and prevent the development of an acidic hydrolytic environment. In addition, the pathogens inhibit the formation of phagolysosomes by preventing the fusion of phagosomes with cellular lysosomes (by sulfatide). On the other hand, surviving inseminated bacilli are transported by these white cells to the regional lymph nodes and continue to divide intracellularly. If the primary lesion is not contained by host defense, a tubercle (granuloma) will form. At this time, a cell-mediated immune response will begin, including a delayed-type hypersensitivity reaction to tuberculin protein. This can lead to a positive tuberculin (PPD) skin test reaction. Tubercle bacilli do not produce adhesion molecules and enjoy a planktonic life even after repeated division. Thus, clinically, the bacilli do not produce biomaterial-centered infection (Table 5) $[3,9,11]$.

\section{Antibiotic Therapy}

Antibiotics should be selected on the basis of culture. However, if the culture fails, appropriate antibiotics should be selected on the basis of textbook recommendations (Table 9). Before drug administration, the drug spectrum should be confirmed, and a bacteriocidal drug is preferable as a first-choice drug to a bacteriostatic drug. Drug administration should be continued until all the clinical symptoms and signs subside and the laboratory data become normalized. For the treatment of most pyogenic infections, a single antibiotic is appropriate, and infrequently a two-drug combination therapy is adopted. In the case of tuberculosis, a single antibiotic attacking only one target should not be prescribed because of its ineffectiveness and also because of early development of drug

Table 6. Bacterial resistances to various classes of clinically used antibiotics

\begin{tabular}{|c|c|c|c|c|c|c|c|}
\hline Antibiotic & Structural class & Target & Mutant/plasmid & Efflux & Porin & Inact & Target alteration \\
\hline Ampicillin & Penicillin & E & $+/+$ & Yes & Yes & Yes & Yes \\
\hline Ceftriaxone & Cephalosporin & $E$ & $+/+$ & Yes & Yes & Yes & Yes \\
\hline Imipenem & Carbapenems & $E$ & $+/+$ & Yes & Yes & Yes & Yes \\
\hline Fosfomycin & Phosphonic acid & $E$ & $+/+$ & & Yes & Yes & \\
\hline Gentamicin & Aminoglycoside & $E$ & $+/+$ & Yes & & Yes & Yes \\
\hline Chloramphenicol & Phenylpropanoid & R & $+/+$ & Yes & & Yes & Yes \\
\hline Tetracycline & Polyketide (II) & $\mathrm{R}$ & $+/+$ & Yes & & & Yes \\
\hline Erythromycin & Macrolide & $\mathrm{R}$ & $+/+$ & Yes & & Yes & Yes \\
\hline Clindamycin & Lincosamide & R & $+/+$ & & & Yes & Yes \\
\hline Synercid & Streptogramin & R & $+/+$ & Yes & & Yes & Yes \\
\hline Telithromycin & Ketolide & R & $+/+$ & Yes & & Yes & Yes \\
\hline Ciprofloxacin & Fluoroquinolone & D & $+/+$ & Yes & & & Yes \\
\hline Vancomycin & Glycopeptide & $E$ & $+/+$ & & & & Yes \\
\hline Sulflsoxazole & Sulfonamide & $M$ & $+/+$ & & & & \\
\hline Trimethoprim & - & $M$ & $+/+$ & & & & \\
\hline Rifampin & Ansamycin & $P$ & $+/+$ & & & Yes & Yes \\
\hline Fusidic acid & Steroid & $\mathrm{T}$ & $+/+$ & Yes & & & Yes \\
\hline Linezolid & Oxazolidinone & $\mathrm{R}$ & $+/-$ & & & & Yes \\
\hline Novobiocin & Coumarin & $D$ & $+/+$ & & & & Yes \\
\hline Isoniazid & - & M & $+/-$ & & & & \\
\hline Pyrazinamide & - & $M$ & $+/-$ & & & & \\
\hline Nitrofurantoin & Nitrofuran & $M$ & $+1-$ & & & Yes & \\
\hline Polymyxin & Peptide & $E$ & $+/-$ & Yes & & & Yes \\
\hline Capreomycin & Peptide & $\mathrm{R}$ & $+/-$ & & & Yes & Yes \\
\hline Mupirocin & Pseudomonic acid & $\mathrm{T}$ & $-/+$ & & & & Yes \\
\hline
\end{tabular}

E, cell wall; $R$, ribosome; $D$, replication; $M$, metabolism; $P$, RNA polymerase; $T$, translation. 
Table 7. Microbial sources of some antibiotics

\begin{tabular}{|ll|}
\hline $\begin{array}{l}\text { Microorganism } \\
\text { Bacteria }\end{array}$ & \multicolumn{1}{c|}{ Antibiotic } \\
\hline Streptomyces various species & Amphotericin B \\
\hline & Chloramphenicol \\
& Erythromycin \\
\hline & Kanamycin \\
\hline & Neomycin \\
\hline & Nystatin \\
\hline Rifampin \\
\hline Bicromonospora various species & Streptomycin \\
\hline Penicillium various species & Tetracyclines \\
\hline Fungious species & Vancomycin \\
\hline & Bacitracin \\
\hline & Polymyxins \\
\hline & Griseofulvin \\
\hline & Penicillin \\
\hline & Cephalosporins \\
\hline & \\
\hline
\end{tabular}

resistance. At a minimum, a combination of at least three drugs should be prescribed at the start. The combination therapy can target at least two sites, or three or four sites for a four-drug combination (Tables 6-11).

\section{Bacterial Structural Targets of Antibiotics (Fig. 7)}

\section{Cellular replication}

Ciprofloxacin (fluoroquinolone class), Novobiocin (coumarin class)

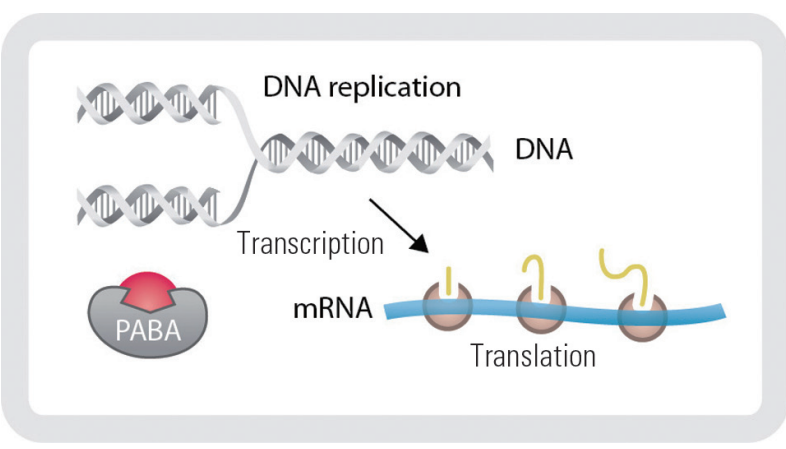

Fig. 7. Summary of the targets used for the development of antibiotics.

Table 8. Gram-positive organisms; initial choice of antibiotics for therapy (adult doses)

\begin{tabular}{|c|c|c|}
\hline Organism & First choice of antibiotics & Alternative antibiotics \\
\hline \multicolumn{3}{|l|}{ Methicillin-sensitive } \\
\hline Staphylococcus aureus & Nafcillin (2 g every 4 hr) or clindamycin (900 mg every 8 hr) & Cefazolin or vancomycin \\
\hline $\begin{array}{l}\text { Coagulase-negative } \\
\text { Staphylococcus species }\end{array}$ & Nafcillin (2 g every 6 hr) or clindamycin (900 mg every 8 hr) & Cefazolin or vancomycin \\
\hline \multicolumn{3}{|l|}{ Methicillin-resistant } \\
\hline Staphylococcus aureus & Vancomycin (1 g every $12 \mathrm{hr}$ ) or linezolid (600 mg every $12 \mathrm{hr}$ ) & $\begin{array}{l}\text { Trimethoprim-sulfamethoxazole or minocycline } \\
\text { with or without rifampin }\end{array}$ \\
\hline $\begin{array}{l}\text { Coagulase-negative } \\
\text { Staphylococcus species }\end{array}$ & Vancomycin (1 g every $12 \mathrm{hr}$ ) or linezolid (600 mg every $12 \mathrm{hr}$ ) & $\begin{array}{l}\text { Trimethoprim-sulfamethoxazole or minocycline } \\
\text { with or without rifampin, clindamycin }{ }^{\text {a) }}\end{array}$ \\
\hline $\begin{array}{l}\text { Group-A Streptococcus or } \\
\text { Streptococcus pyogenes }\end{array}$ & Penicillin $\mathrm{G}\left(2 \times 10^{6} \mathrm{U}\right.$ every $4 \mathrm{hr}$ ) or ampicillin (2 g every $6 \mathrm{hr}$ ) & Clindamycin, cephalosporine or vancomycin \\
\hline $\begin{array}{l}\text { Group-B Streptococcus or } \\
\text { Streptococcus agalactiae }\end{array}$ & Penicillin $\mathrm{G}\left(2 \times 10^{6} \mathrm{U}\right.$ every $4 \mathrm{hr}$ ) or ampicillin ( $2 \mathrm{~g}$ every $6 \mathrm{hr}$ ) & Clindamycin, cephalosporine or vancomycin \\
\hline \multicolumn{3}{|l|}{ Sensitive } \\
\hline Streptococcus pneumoniae & Penicillin $\mathrm{G}\left(2 \times 10^{6} \mathrm{U}\right.$ every $\left.4 \mathrm{hr}\right)$ & Clindamycin or erythromycin \\
\hline \multicolumn{3}{|l|}{ Intermediate } \\
\hline Streptococcus pneumoniae & Cefotaxime (1 g every $8 \mathrm{hr}$ ) & Clindamycin or erythromycin \\
\hline \multicolumn{3}{|l|}{ Resistant } \\
\hline Streptococcus species & Vancomycin (1g every $12 \mathrm{~h}$ ) or levofloxacin (500mg daily) & Quinupristin/dalfopristin or linezolid \\
\hline \multicolumn{3}{|l|}{ Sensitive } \\
\hline Enterococcus species & Ampicillin (1 g every $6 \mathrm{hr})^{b)}$ or vancomycin (1 g every $12 \mathrm{hr}$ ) & Ampicillin-sulbactam linezolid \\
\hline \multicolumn{3}{|l|}{ Resistant } \\
\hline Enterococcus faecium & $\begin{array}{l}\text { Quinupristin/dalfopristin (7.5 mg/kg every } 8 \mathrm{hr} \text { ) or linezolid (600 } \\
\text { mg every } 12 \mathrm{hr} \text { ) }\end{array}$ & Chloramphenicol and rifampin \\
\hline
\end{tabular}

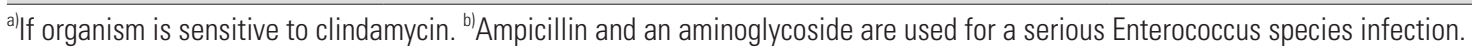


Table 9. Gram-Negative Organisms: Initial choice of antibiotics for therapy (adult doses)

\begin{tabular}{|c|c|c|}
\hline Organism & First choice of antibiotics & Alternative antibiotics \\
\hline Acinetobacter species & $\begin{array}{l}\text { Ceftazidime ( } 1 \mathrm{~g} \text { every } 8 \mathrm{hr} \text { ) and levofloxacin ( } 500 \mathrm{mg} \text { daily) } \\
\text { or imipenem ( } 500 \mathrm{mg} \text { every } 6 \mathrm{hr} \text { ) }\end{array}$ & Ampicillin-sulbactam \\
\hline Enterobacter species & Cefotaxime ( $1 \mathrm{~g}$ every $6 \mathrm{hr}$ ) or imipenem (500 mg every $6 \mathrm{hr}$ ) & Levofloxacin, mezlocillin, or ticarcillin-clavulante \\
\hline Escherichia coli & Ampicillin-sulbactam (3 g every $6 \mathrm{hr}$ ) & $\begin{array}{l}\text { Cefazolin, levofloxacin, gentamicin, or trime- } \\
\text { thoprim-sulfamethoxazole. }\end{array}$ \\
\hline Haemophilus influenza & $\begin{array}{l}\text { Cefotaxime ( } 1 \mathrm{~g} \text { every } 8 \mathrm{hr} \text { ) or ampicillin-sulbactam } \\
(3 \mathrm{~g} \text { every } 6 \mathrm{hr})\end{array}$ & $\begin{array}{l}\text { Levofloxacin, trimethoprim-sulfamethoxazole, } \\
\text { ampicillin }^{\text {al) }} \text { or azithromycin }\end{array}$ \\
\hline Klebsiella species & Cefotaxime (1 g every 8 hr) or levofloxacin (500 mg daily) & Ampicillin-sulbactam or gentamicin \\
\hline Proteus mirabilis & Ampicillin (1 g every 6 hr) or levofloxacin (500 mg daily) & $\begin{array}{l}\text { Cefazolin, trimethoprim-sulfamethoxazole or } \\
\text { gentamicin }\end{array}$ \\
\hline $\begin{array}{l}\text { Proteus vulgaris, Proteus rettgeri, } \\
\text { or Morganella morganii }\end{array}$ & $\begin{array}{l}\text { Cefotaxime ( } 2 \text { g every } 8 \mathrm{hr} \text { ) or imipenem ( } 500 \mathrm{mg} \text { every } 6 \mathrm{hr} \text { ) } \\
\text { or levofloxacin ( } 500 \mathrm{mg} \text { daily) }\end{array}$ & Mezlocillin, gentamicin, or ticarcillin-clavulanate \\
\hline Neisseria gonorrhoeae & $\begin{array}{l}\text { Ceftriaxone (one intramuscular injection of } 125 \mathrm{mg} \text { ) and } \\
\text { azithro-mycin (one dose of } 1 \mathrm{~g} \text { daily) }\end{array}$ & Levofloxacin and azithromycin \\
\hline Providencia species & $\begin{array}{l}\text { Cefotaxime ( } 2 \text { g given intravenously every } 8 \mathrm{hr} \text { ) or } \\
\text { levofloxacin ( } 500 \mathrm{mg} \text { daily) }\end{array}$ & $\begin{array}{l}\text { Trimethoprim-sulfamethoxazole, amikacin or } \\
\text { imipenem }\end{array}$ \\
\hline Pseudomonas aeruginosa & $\begin{array}{l}\text { Cefepime }^{\text {b) }}(2 \mathrm{~g} \text { every } 12 \mathrm{hr} \text { ) or piperacillin } \\
\text { (2 g every } 6 \text { hr or imipenem ( } 500 \text { mg every } 6 \text { hr) }\end{array}$ & $\begin{array}{l}\text { Ticarcillin-clavulanate, tobramycin, amikacin, or } \\
\text { ciprofloxacin }{ }^{c)}\end{array}$ \\
\hline Serratia marcescens & Cefotaxime ( 2 g every $6 \mathrm{hr}$ ) & Levofloxacin, gentamicin, or imipenem \\
\hline
\end{tabular}

${ }^{a)}$ Should be used for non- $\beta$-lactamase-producing strains of Haemophilus influenza; ${ }^{\text {b) }}$ For a serious infection, cefepime or piperacillin should be used with an aminoglycoside-gentamicin or tobramycin ( $5 \mathrm{mg} / \mathrm{kg} /$ day); ${ }^{\mathrm{c}}$ Increasing resistance to the quinolones, including ciprofloxacin.

Table 10. Anaerobic Organisms: Initial choice of antibiotics for therapy (adult doses)

\begin{tabular}{|c|c|c|}
\hline Organism & First choice of antibiotics & Alternative antibiotics \\
\hline Bacteroides fragilis group & Clindamycin (900 mg every $8 \mathrm{hr}$ ) or metronidazole (500 mg every 8 hr) & Ampicillin-sulbactam, ticarcillin-clavulanic acid \\
\hline Prevotella species & Clindamycin (900 mg every 8 hr) or metronidazole (500 mg every 8 hr) & Ampicillin-sulbactam, cefotetan \\
\hline Peptostreptococcus species & 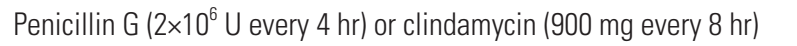 & Clindamycin, metronidazole \\
\hline Clostridium species & Clindamycin (900 mg every $8 \mathrm{hr}$ ) or penicillin $\mathrm{G}\left(2 \times 10^{6} \mathrm{U}\right.$ every $\left.4 \mathrm{hr}\right)$ & Ampicillin-sulbactam, metronidazole \\
\hline
\end{tabular}

\section{Cell wall}

Ampicillin, Ceftriaxone, Imipenem, Ethambutol, Vancomycin, Polymyxin, Isoniazid (INH), Fosfomycin

\section{Cell metabolism}

Sulfisoxazole, Trimethoprim, Nitrofurantoin, Isoniazid, Pyrazinamide

\section{RNA polymerase}

Rifampin

\section{Ribosomes}

Gentamicin, Chloramphenical, Tetracycline, Erythromy- cin, Clindamycin, Synacid, Telithromycin, Linezolid

\section{Translation}

Fusidic acid, Mupriocin, Streptomycin

Antibiotic therapy for causative pathogens is listed in Table 6.

\section{Structural targets of antibiotics against M. tuberculosis}

Isoniazid, Ethambutol for cell membrane

Isoniazid, Pyrazinamide for metabolism

Rifampin for RNA polymerase

Streptomycin for translocation

- Isoniazid is very effective against $M$. tuberculosis because 
Table 11. Properties of Some Common Antibiotics

\begin{tabular}{|c|c|c|c|}
\hline Drug & Primary effect & Spectrum & Side effects \\
\hline Ampicillin & Cidal & Broad (Gram+, some Gram-) & Allergic responses, diarrhea, anemia \\
\hline Bacitracin & Cidal & Narrow (Gram+) & Renal injury if injected \\
\hline Carbenicillin & Cidal & Broad (Gram+, many Gram-) & Allergic responses, nausea, anemia \\
\hline Cephalosporins & Cidal & Broad (Gram+, some Gram-) & Allergic responses, thrombophlebitis, renal injury \\
\hline Chloramphenicol & Static & Broad (Gram+, Gram-; Rickettsia and Chlamydia) & Depressed bone marrow function, allergic reactions \\
\hline Ciprofloxacin & Cidal & Broad (Gram+, Gram-) & Gastrointestinal upset, allergic responses \\
\hline Clindamycin & Static & Narrow (Gram+, anaerobes) & Diarrhea \\
\hline Dapsone & Static & Narrow (mycobacteria) & Anemia, allergic responses \\
\hline Erythromycin & Static & Narrow (Gram+, mycoplasma) & Gastrointestinal upset, hepatic injury \\
\hline Gentamicin & Cidal & Narrow (Gram-) & Allergic responses, nausea, loss of hearing, renal damage \\
\hline Isoniazid & Static & Narrow (mycobacteria) & Allergic reactions, gastrointestinal upset, hepatic injury \\
\hline Methicillin & Cidal & Narrow (Gram+) & Allergic responses, renal toxicity, anemia \\
\hline Penicillin & Cidal & Narrow (Gram+) & Allergic responses, nausea, anemia \\
\hline Polymyxin B & Cidal & Narrow (Gram-) & Renal damage, neurotoxic reactions \\
\hline Rifampin & Static & Broad (Gram-, mycobacteria) & Hepatic injury, nausea, allergic responses \\
\hline Streptomycin & Cidal & Broad (Gram+, Gram-; mycobacteria) & Allergic responses, nausea, loss of hearing, renal damage \\
\hline Sulfonamides & Static & Broad (Gram+, Gram-) & Allergic responses, renal and hepatic injury, anemia \\
\hline Tetracyclines & Static & Broad (Gram+, Gram-; Rickettsia and chlamydia) & $\begin{array}{l}\text { Gastrointestinal upset, teeth discoloration, renal and } \\
\text { hepatic injury }\end{array}$ \\
\hline Trimethoprim & Cidal & Broad (Gram+, Gram-) & Allergic responses, rash, nausea, leukopenia \\
\hline Vancomycin & Cidal & Narrow (Gram+) & $\begin{array}{l}\text { Hypotension, neutropenia, kidney damage, allergic reac- } \\
\text { tions }\end{array}$ \\
\hline
\end{tabular}

of a mechanism that seems to inhibit the synthesis of mycolic acid.

- Ethambutol with isoniazid inhibits the incorporation of mycolic acid into the growing bacterial cell wall.

- Rifampin inhibits RNA polymerase activity. The rifampin-binding site is on the RNA polymerase beta subunit (Fig. 8). Once the activity of this molecule is blocked, there can be no transcription and therefore no protein synthesis, which is a lethal event.

- Pyrazinamide affects cell metabolism.

* In initiation of antituberculous chemotherapy, monotherapy should not be done because of early occurrence of drug resistance. Combination therapy with more than two drugs must be practiced.

Recently, multidrug-resistant tuberculosis (MDR) has become a clinical issue, particularly extremely drug-resistant tuberculosis (XDR). XDR is defined as resistance to isoniazid, rifampin, a fluoroquinolone, and an injectable agent such as an aminoglycoside. Treatment of both MDR and XDR tuberculosis requires a specialist in the use of

\section{A. Rifampin}

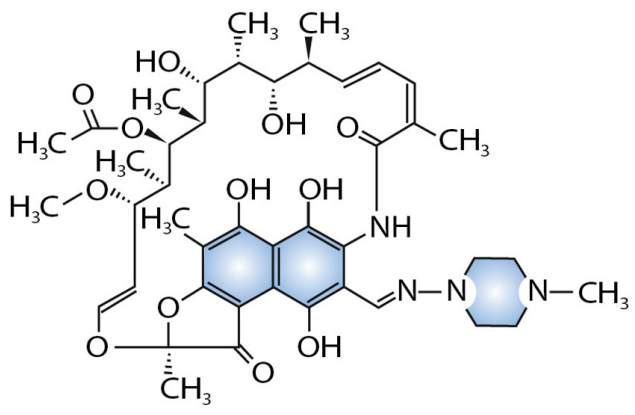

B. Rifampin and RNA polymerase

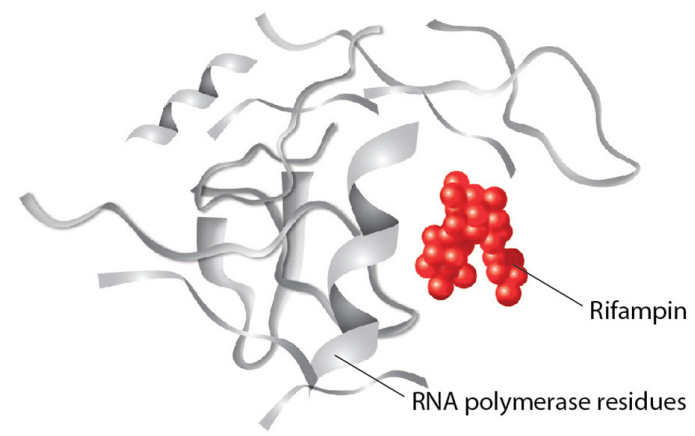

Fig. 8. Action of rifampin on RAN polymerase (target site). 
multiple second-line agents for an extended period of time (usually 18-24 months). The failure rate in treatment of XDR tuberculosis is high. The most common cause of both MDR and XDR tuberculosis is failure to treat the initial episode of drug-susceptible tuberculosis appropriately.

\section{Bacterial Mutation Against Antibiotics}

Pyogenic bacteria in general have a very short generation time. They can quickly grow into large populations. Consequently, the potential for rapid spontaneous mutation is higher. The more antibiotic is used, the greater the occurrence of resistance. The mechanisms of acquired resistance include inactivation of the antibiotic, usually by enzymatic breakdown; efflux pumping of the antibiotic; modification of the antibiotic target; alteration of the pathway; and modification of the target ribosome.

\section{Conclusions}

I suggest that the reader should well understand the anatomy of infective bacterial cells, their functional behavior, and the antibiotic therapy needed to win the war against the tiny invaders and leave the host unharmed. My views on infection control may be unsound and my voice on this subject may sound unbearable. I am convinced that a cure or control of infection only by the host's own defense system, including phagocytic activity and the infectionrelated activated immune system, without antibiotic assistance, cannot be expected.

In the future, both defense systems should be improved or strengthened further. Present medical science has encountered limitations in augmenting the physiological defense system, and all the measures taken to improve the host's own defense system have been ineffective. Is there no hope of improving the physiological defense system? A currently known unique method of enhancing host phagocytic activity is to nourish the infected host with a high-calorie and high-protein diet. Antibiotics only kill the pathogen and do not contribute to promotion of the host defense system. My suggestion is that scientists should direct their studies not only to developing potent new antibiotics that will never give rise to drug-resistant mutants, but also to developing a very competitive immune system that can suppress or control infection without the aid of antibiotics. It is my humble wish that someday scientists will develop a very potent immortal phagocytic cell line that will carry various germicidal enzymes.

\section{Conflict of Interest}

No potential conflict of interest relevant to this article was reported.

\section{References}

1. Moon MS, Rhee SK, Kang YK. Harrington rods in treatment of active spinal tuberculosis with kyphosis. J Western Pac Orthop Assoc 1986;23:53-8.

2. Kim YY. Replacement arthroplasty using Charnley prosthesis in old tuberculosis of the hip: clinical experience with 8-10 year follow-up. In: Sharnmugasundariom TK, editor. Current concepts in bone \& joint tuberculosis. Madras: India; 1983. p.64-73.

3. Oga M, Arizono T, Takasita M, Sugioka Y. Evaluation of the risk of instrumentation as a foreign body in spinal tuberculosis. Clinical and biologic study. Spine (Phila Pa 1976) 1993;18:1890-4.

4. Strelkauskas AJ, Strelkauskas J, Moszyk-Strelkauskas D. Microbiology: a clinical approach. New York: Garland Science; 2010.

5. Gladwin $M$, Trattler B. Clinical microbiology made ridiculously_simple. Miami: Medmaster; 2009.

6. Moon MS. Managing tuberculosis of the spine. Med Progress 2004;31:593-602.

7. Slonczewski JL, Foster JW, Gillen KM. Microbiology an evolving science. New York: Norton; 2011.

8. Moon MS, Kim SS, Moon HL, Kim DH. Mycobacterium tuberculosis in spinal tuberculosis. Asian Spine J 2017;11:138-49.

9. Ha KY, Chung YG, Ryoo SJ. Adherence and biofilm formation of Staphylococcus epidermidis and Mycobacterium tuberculosis on various spinal implants. Spine (Phila Pa 1976) 2005;30:38-43.

10. Moon MS, Kim SS, Lee SY, et al. Preoperative nutritional status of the surgical patients in Jeju. Clin Orthop Surg 2014;6:350-7.

11. Min KW. Pathology of acquired immunodeficiency syndrome. J Korean Med Sci 1997;12:171-84. 